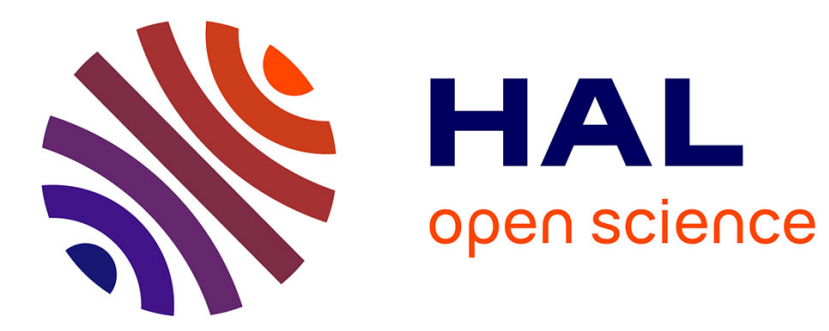

\title{
Combustion and fire retardance in polymeric materials
}

\author{
G. Camino, M. Luda, L. Costa
}

\section{To cite this version:}

G. Camino, M. Luda, L. Costa. Combustion and fire retardance in polymeric materials. Journal de Physique IV Proceedings, 1993, 03 (C7), pp.C7-1539-C7-1542. 10.1051/jp4:19937240 . jpa-00251878

\section{HAL Id: jpa-00251878 https://hal.science/jpa-00251878}

Submitted on 1 Jan 1993

HAL is a multi-disciplinary open access archive for the deposit and dissemination of scientific research documents, whether they are published or not. The documents may come from teaching and research institutions in France or abroad, or from public or private research centers.
L'archive ouverte pluridisciplinaire HAL, est destinée au dépôt et à la diffusion de documents scientifiques de niveau recherche, publiés ou non, émanant des établissements d'enseignement et de recherche français ou étrangers, des laboratoires publics ou privés. 


\title{
Combustion and fire retardance in polymeric materials
}

\author{
G. CAMINO, M.P. LUDA and L. COSTA \\ Dipartimento di Chimica Inorganica, Chimica Fisica e Chimica dei Materiali dell'Università, \\ Via P. Giuria 7, 10125 Torino, Italy
}

\begin{abstract}
The use of organic polymeric materials is limited in many applications because of fire hazard. Fire retardant systems have been found which reduce this hazard below acceptable levels. The development of more efficient systems is constantly pursued to meet the demand for ever safer materials. This involves the difficult problems of the testing methods and of the mechanistic approach which should supply information for progressing in this task. Examples of mechanistic studies on halogen based or intumescent fire retardant are illustrated.
\end{abstract}

\section{INTRODUCTION}

However unique a polymeric material might be, as far as properties are concerned, its use is likely to be restricted in many applications, because of fire hazard.

Indeed, at least $50-60 \%$ of the polymeric materials now fabricated, must show some degree of fire retardance.

Organic polymers can initiate or propagate fires because, on exposure to heat, they undergo thermal degradation to volatile combustible products. If the concentration of the degradation products in the air is within flammability limits, they can ignite either spontaneously, if their temperature is large enough, or by effect of an ignition source such as a spark or a flame.

The combustion process continues then to complete consumption of the material, if the heat fed back from the flame to the polymer is sufficient to keep its rate of degradation above the minimum value for feeding the flame itself. Otherwise, the cyclic combustion process stops and the flame extinguishes.

Organic materials suitable for fabrication of articles, cannot be made non combustible. However, their ignition can be delayed and/or the rate of combustion decreased, by means of so called "fire retardants". The ultimate aim of fire retardants is at reducing the heat transferred to the polymer, below the limit for self-sustained combustion.

Fire retardant structures are introduced in the polymer either by means of additives or by modification of its molecular structure (e.g. by copolymerisation or chemical reaction). The additive approach is most used and is the one referred to in the following.

The empirical approach was used in the early stage of the development of fire retardant materials. However, to meet the ever increasing performances required by regulations, highly effective fire retardant systems must be designed, for which mechanistic knowledge of combustion and fire retardance is necessary. 


\section{FLAMMABILITY EVALUATION}

The evaluation of "flammability" of polymeric materials is in turn necessary for mechanistic studies. However, flammability is not a scientific term in relation to these materials because there is not a single parameter which can measure it. In practice, a number of parameters is used to define the relative flammability of polymers such as: ease of ignition, rate of flame spread etc.

Furthermore, the combustion behaviour of polymeric materials is not an intrinsic property depending solely on its chemical structure. In fact, the behaviour of the material depends as well on extrinsic factors such as heat irradiance, ventilation, shape, size and density of the specimen, etc.

Scenarios in large scale fires are extremely variable. Therefore it is not possible to define a unique set of conditions in which the parameters related to flammability should be measured, to predict the behaviour of the material in a real fire. These difficulties have led to the proliferation of flammability tests for polymers, to about 800 worldwide [1].

The pragmatic approach most often followed in these tests, involves the use of a well defined fire model in which the combustion is carried out in carefully controlled conditions. This ensure reproducibility of results which is essential for comparison of materials. However, the test cannot generally be used to predict the behaviour of the materials in fires.

The "oxygen index test", among established tests, is the most useful for mechanistic studies, because it ranks materials on a quantitative basis and is very reproducible [2]. The index is the minimum oxygen concentration in air, required for self-sustained combustion of a downburning vertical specimen.

The "cone calorimeter" is a relatively recently developed test which supplies an integrated set of physical chemical parameters of the combustion which can be of fundamental value in mechanistic studies once it will become completely established and widely spread.

\section{THE MECHANISTIC APPROACH}

The mechanistic study of polymer combustion and fire retardance is a complex multidisciplinary topic, encompassing physical and chemical phenomena occurring in the gas and condensed phase. Thus, aspects involved are physical chemistry of flames and thermal degradation of polymers, respectively.

The processes occurring in the condensed phase are of primary importance because they originate the volatile species which feed the flame. Techniques and methods of general use in the study of thermal degradation of polymers, are applied to the study of condensed phase processes in combustion and fire retardance.

However, thermal degradation of polymers may strongly depend on experimental conditions such as temperature, type of atmosphere, rate of heating, pressure, etc. In order to obtain mechanistic information which are relevant to the understanding of the combustion process, the thermal degradation must be carried out in conditions simulating those to which the polymer is exposed during combustion.

Generally, reference is made to the fire model of the method used to evaluate the combustion behaviour of the fire retardant under study, e.g. the oxygen index test. A most important parameter is the concentration of oxygen on the surface of the burning polymer and hence the occurrence of thermal oxidation in the condensed phase. This is a most controversial point which might be rationalised so far by assuming that it depends on the type of polymer and burning conditions [3].

A recent overview on literature data, shows that thermal degradation studies should be carried out in a number of different conditions, in order to supply more reliable data on mechanisms of combustion [3]. 


\section{HALOGEN-BASED FIRE RETARDANTS}

The most effective and versatile fire retardant systems developed so far are based on chlorine or bromine containing compounds [4]. Effectiveness can be considerably enhanced if the halogenated compound is used in combination with metal oxides, such as antimony trioxide. This "synergistic" effect is due to reactions between the halogenated compound and the metal oxide which leads to halogenation of the oxide to intermediate oxyhalides and finally to volatile metal halides as for example antimony trichloride or tribromide.

The metal halides are inhibitors of the radical chain oxidation occurring in the flame, much more effective than hydrogen halides which would be evolved in the absence of the metal compound. This chemical gas phase action is however not always the dominant fire retardant action in these systems. It was indeed shown that halogen based fire retardants may, more often than not, interact with the polymer matrix on heating, altering its degradation process and hence its combustion behaviour by a condensed phase action [3-5].

Whichever the predominant fire retardant action in synergistic systems, its mechanism will primarily depend on the species formed by the reactions between the halogen compound and the metal oxide. Recent studies showed that the nature of such species depends on the competition between chemical halogenation of the metal oxide and thermal disproportionation of metal oxyhalides to metal halide and lower-halogen content oxyhalide (or metal oxide) [3]. The result of the competition varies with the temperature of the condensed phase during burning. These data will be of basic importance in the study of the interactions between synergistic halogenated fire retardants and polymer matrix which is still in its early steps [3].

\section{INTUMESCENT FIRE RETARDANTS}

The awareness of possible negative side effects in halogen-based fire retardants, has recently increased the interest for halogen-free systems, among which the intumescent ones seem to be most promising $[3,6,7]$. A foamed multicellular char is formed by intumescent systems on heating which shields the underlying material from the action of the flame.

Typical intumescent systems, derived from coating technology, are based on polyhydric compounds combined with a compound liberating an inorganic acid on heating, such as ammonium polyphosphate. These mixtures, added to polymers which degrade quantitatively to volatile products, as for example polypropylene, provide fire retardance by producing the intumescent char while the polymer is consumed.

The mechanistic study of intumescent systems involves the study of the chemistry of the charring reaction, the occurrence of the foaming process and the characteristics of the char. In the case of pentaerythrytol-ammonium polyphosphate mixtures, it was shown that intumescence is due to pentaerythrytol phosphate structures formed on heating [8]. The detailed study of the thermal degradation of a model compound for these structures showed that charring occurs through pyrolysis and hydrolysis of the phosphate ester bonds, followed by polymerisation or condensation of the resulting structures $[9,10]$.

The volatilisation of water, hydrocarbons, aldehydes evolved while charring occurs, leads to foaming of the char with formation of spherical closed cells. Most often, so called "blowing agents" are added to the system which decompose on heating, giving a large volume of gaseous products. The choice of the blowing agent must take into account that the temperature at which it should decompose and give the gases should match favourably with the charring process.

For example, urea was shown to deplete instead of increasing the intumescent effect of pentaerythrytol-ammonium polyphopsphate mixtures added to polypropylene. This is due to the fact that urea gives a large amount of gases on decomposition which occurs however at lower temperature than that of charring of the additive [11]. 


\section{CONCLUSIONS}

Mechanistic studies provide information which are necessary to develop highly effective fire retardant systems tailor-made to the type of polymer and/or to the combustion behaviour required by the envisaged application.

This approach requires complex studies of the basic aspects of polymer combustion and fire retardance which have not yet been carried out to a sufficient extent. On the other hand this is the only way that can lead us to control satisfactorily the fire hazard of polymers.

\section{REFERENCES}

[1] W. Becker, Polym. Deg. and Stab., 30, 141 (1990).

[2] C.P. Fenimore, in "Flame-retardant polymeric materials" (M. Lewin, S.M. Atlas and E.M. Pearce (Eds.)), Plenum Press, New York, 1, 371 (1975).

[3] G. Camino, L. Costa, M.P. Luda di Cortemiglia, Polym. Deg. and Stab., 33, 131 (1991).

[4] C.F. Cullis and M.M. Hirschler, "The combustion of organic polymers", Clarendon Press, Oxford (1981).

[5] G. Camino, in "Developments in polymer degradation" (N. Grassie, (Ed.)), Applied Science Publishers, London, 7, 221 (1987).

[6] G. Camino, L. Costa, Rev. Inorg. Chem., 8, 69 (1986).

[7] G. Camino, L. Costa, G. Martinasso, Polym. Deg. and Stab., 23, 359 (1989).

[8] G. Camino, L. Costa, L. Trossarelli, F. Costanzi, A. Pagliari, Polym. Deg. and Stab., 12, 213 (1985).

[9] G. Camino, G. Martinasso, L. Costa, Polym. Deg. and Stab., 27, 285 (1990).

[10] G. Camino, G. Martinasso, L. Costa, R. Gobetto, Polym. Deg. and Stab., 28, 17 (1990).

[11] G. Camino, L. Costa, L. Trossarelli, Polym. Deg. and Stab., 7, 221 (1984). 